\title{
Longitudinal Effects of Entry-Level Truck Driver Training Methods
}

\author{
R. J. Hanowski \\ Virginia Tech Transportation Institute \\ USA
}

\begin{abstract}
This study evaluated the effectiveness of utilizing a driving simulator for entry-level truck driver training and testing. The $\mathbf{1 0 7}$ participants were from one of four groups: conventional 8-week certified course, conventional 8-week certified course with 60 percent of driving in a simulator, informal training with friends/relatives, and commercial's driver license [CDL] test focused short courses. A follow-on analysis, which is the focus of this paper, tested drivers approximately 4 months after they had acquired their CDL, to determine the longitudinal effects of training method on driver performance. Twenty-two drivers were eligible for the follow-on analysis, which involved both simulated and real-vehicle (behind the wheel; BTW) road and range tests. The conventional group had lower scores at the 4month follow-up as compared to tests at the condusion of entrylevel training. Participants in the simulator training group had lower scores in both the simulated road and BTW road tests at the 4-month follow-up test compared to the same tests at the conclusion of entry-level training. Generally, for all groups, the follow-up test scores were lower than the original scores during the entry-level tests. However, similar to the entry-level tests, the conventional and simulator groups performed better on the follow-up road tests than the informal and CDL-focused groups. The results highlight the long term benefits of 8 -week courses as compared to informal training and CDL-focused short courses.
\end{abstract}

Keywords-simulator training; simulator validity; truck driver training; longitudinal training effects

\section{INT RODUCTION}

Truck driving training simulators is becoming increasingly available. Reported in 2000, two countries in Europe have implemented simulators as part of truck driver training programs [1]. Programs in France and Sweden offer truck driver training curricula that combines simulator and computer-based training, in addition to on-road, behind the wheel (BTW) training in real vehicles. Successful implementation of simulator truck driver training in Europe has led some North A merican based truck fleets to explore the use of simulator-based training [2].

With an interest in evaluating the efficacy of simulator training for US-based truck drivers, the current study evaluated four training approaches:

- Conventional Training - Defined as conventional, BTW (i.e., real-world) training certified by the Professional Truck Driver Institute (PTDI; 1999).

- Simulator Training - Defined for this study as simulator-based, PTDI-certified, training with $58 \%$ of total driving time spent in a simu lator and $42 \%$ of total driving time spent BTW.

\author{
J. F. Morgan \\ Battelle Memorial Institute \\ USA
}

- Informal Training - Defined as unstructured training provided outside of formal training settings, with nonprofessional trainers (e.g., drivers trained by friends or family members).

- $\quad C D L$-focused Training - Defined as short, CDL-exam focused truck-driver-training courses.

Details of the study method and simulator used in the study can be found elsewhere [3]. Briefly, the study was conducted to assess how these four entry-level training methods compared in terms of skill acquisition and forward transfer of training to on-the-job driver performance. The current paper highlights these findings from [3] with respect to the longitudinal effects across the four training approaches.

\section{METHODS}

\section{A. Participants}

As detailed in [3], 107 participants completed the entrylevel testing, including: 33 in the conventional group, 32 in the simulator group, 33 in the CDL-focused group, and 9 in the informal group. All participants in the conventional and simulator groups experienced identical training curricula. In order to be eligible for the longitudinal follow-up, participants were required to be continually-employed in a commercial motor vehicle (i.e., CDL-required) driving position since obtaining their CDL. Due to an economic recession occurring at the time of the study, many CDL operator jobs were lost. This reduced the total number of eligible participants. Thus, a total of 22 participants were eligible for, and completed, the longitudinal follow-up testing.

\section{B. Entry-Level Training Curriculum for Conventional And Simulator Groups}

Participants in the conventional training group received full-curriculum, entry-level training which included 50 hours of BTW training in an actual tractor-trailer and 147 hours of classroom instruction during this PTDI-certified program. The training course lasted 8 weeks, including all classroom instruction (which includes instruction on vehicle systems, theory of vehicle operations, log books, and FMCSA regulations), range driving (i.e., backing maneuvers), and road driving. Similar to the conventional group, participants in the simu lator group followed the same full-curriculum, entry-level training. However, they received 42\% (23 hours) of their practice driving time in a real tractor-trailer and 58\% (32 hours) in a simulator while also receiving the same 147 hours of clas sroom instruction. 


\section{Driving Simulator and BTW Tractor-Trailers}

An FAAC, Inc., model TT-2000-V7 driving simulator was selected for use in this study. This simulator provided a $225^{\circ}$ seamless forward field of view with five forward visual channels. Two rear visual channels provided views through the use of real mirrors (fig. 1). Multiple engine, transmission, and trailer configurations were provided, allowing the simulator to be configured in a similar manner to the BTW vehicle used in that day's driving. Additionally, the training program used three Class-8 tractors with trailers for road use, along with other tractors for range driving that were used for this study. Fig. 2 shows a photo of one of the training road trucks used in the study. Full details of the simulator, simulator scenarios, and BTW tractors and trailers used in the study can be found in [3].
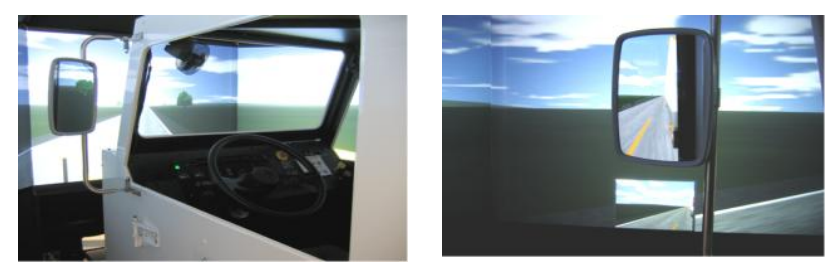

FIGURE I. THETT-2000-V7 DRIVING SIMULATOR (LEFT) ANDTHE REAR VISUAL CHANNEL AS VIEWED THROUGH THE SIMULATOR MIRRORS (RIGHT).

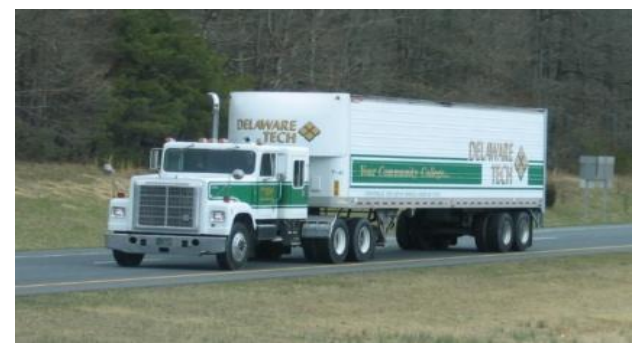

FIGURE II. ONE OF THREE CLASS-8 TRACTORS USED ON ROADS AT THE TEST FACILITY.

\section{Longitudinal Measures}

Though the study included many measures to assess the efficacy of the training approaches (see [3]), the focus of this paper is on the longitudinal measures that were collected to assess whether there were any longer-term impacts of the training approach. Longitudinal performance measures included a 4-5 month post-employment test on both the simulator and BTW road and range tests.

\section{RESULTS}

After 4-5 months post-employ ment, participants returned to the test facility and completed a replication of both BTW and simulator road and range tests. Though 22 participants completed the follow-up testing, one of the drivers experienced simulator sickness and did not complete any of the simulator tests (and thus was excluded from the analysis). The same testing protocol as used to initially assess performance was replicated for this longitudinal test [3]. The status of all entry-level participants is shown in tab. 1, while tab. 2 provides descriptive statistics of the test results. One key finding was that none of the informal training group participants passed the simulator and BTW road tests; however, both of these participants passed the BTW and simu lator range (i.e., backing maneuver) exams.

A pattern can be seen when comparing participants' performance in testing at the conclusion of entry-level training As shown in fig. 3, participants in the conventional group had lower scores at the 4-month follow-up as compared to tests at the conclusion of entry-level training while participants in the simulator training groups had lower scores in both the simulated BTW road tests at the 4-month follow-up test compared to the same tests at the conclusion of entry-level training. Fig. 3 also highlights the failed tests for informal and CDL-focused participants.

TABLE I. STATUS OFPARTICIPANTS FOR FOLLOW-UP TESTING.

\begin{tabular}{|c|l|l|l|l|}
\hline $\begin{array}{c}\text { Training } \\
\text { Group }\end{array}$ & $\begin{array}{c}\text { Participants } \\
\text { Completed } \\
\text { Initial Testing }\end{array}$ & $\begin{array}{c}\text { Participants } \\
\text { Eigible for } \\
\text { Follow-Up }\end{array}$ & $\begin{array}{c}\text { Participan ts } \\
\text { Screened for } \\
\text { Follow-Up }\end{array}$ & $\begin{array}{c}\text { Participants } \\
\text { Completed } \\
\text { 4-Month } \\
\text { Testing }\end{array}$ \\
\hline Conventional & 33 & 10 & 7 & $4 *$ \\
\hline Simulator & 32 & 15 & 15 & 13 \\
\hline Informal & 9 & 8 & 3 & 2 \\
\hline CDL-focus & 33 & 10 & 3 & 3 \\
\hline
\end{tabular}

* One conventional group driver was driving a straight (Class-B) truck at the time of testing.

TABLE II.DESCRIPTIVE STATISTICS FOR FOLLOW-UP TESTING.

\begin{tabular}{|l|l|l|l|l|l|l|}
\hline Training Group & \multicolumn{1}{|c|}{ Test } & \multicolumn{1}{c|}{$\boldsymbol{n}$} & \multicolumn{1}{c|}{ Mean } & \multicolumn{1}{c|}{ SD } & Min & Max \\
\hline Conventional & BTW Road & 4 & 76.8 & 18.8 & 50 & 94 \\
\hline Conventional & BTW Range & 4 & 98.3 & 2.4 & 95 & 100 \\
\hline Conventional & Sim Road & 3 & 59.0 & 15.6 & 50 & 77 \\
\hline Conventional & Sim Range & 3 & 58.3 & 14.4 & 50 & 75 \\
\hline Simulator & BTW Road & 13 & 79.5 & 14.3 & 50 & 95 \\
\hline Simulator & BTW Range & 13 & 95.2 & 6.1 & 81 & 100 \\
\hline Simulator & Sim Road & 13 & 77.9 & 14.0 & 50 & 92 \\
\hline Simulator & Sim Range & 13 & 75.5 & 18.5 & 50 & 98 \\
\hline Informal & BTW Road & 2 & 50.0 & 0.0 & 50 & 50 \\
\hline Informal & BTW Range & 2 & 98.0 & 0.0 & 98 & 98 \\
\hline Informal & Sim Road & 2 & 50.0 & 0.0 & 50 & 50 \\
\hline Informal & Sim Range & 2 & 91.0 & 12.7 & 82 & 100 \\
\hline CDL-Focused & BTW Road & 3 & 63.3 & 23.1 & 50 & 90 \\
\hline CDL-focused & BTW Range & 3 & 96.7 & 4.9 & 91 & 100 \\
\hline CDL-focused & Sim Road & 3 & 50.0 & 0.0 & 50 & 50 \\
\hline CDL-focused & Sim Range & 3 & 63.7 & 23.7 & 50 & 91 \\
\hline
\end{tabular}

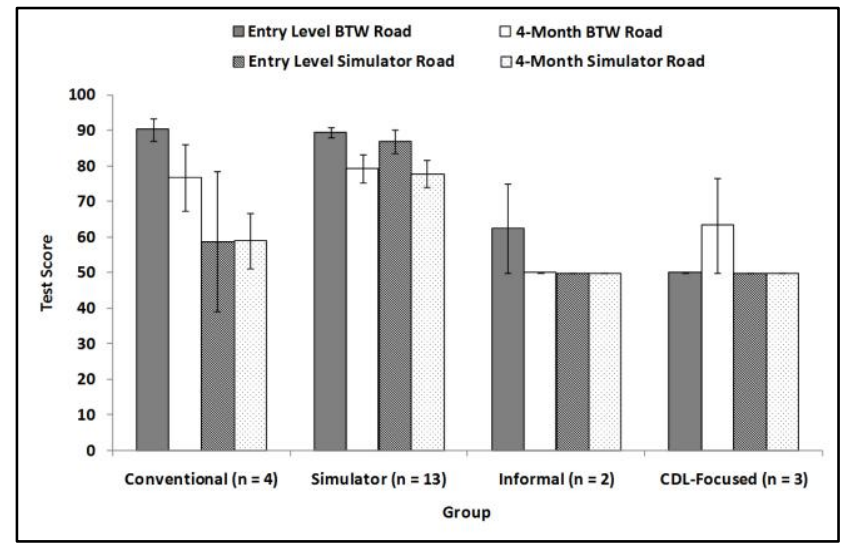

FIGURE III.

ROAD TEST: ENT RY LEVEL AND FOLLOW-UP SCORES BY TEST MODE AND GROUP. NOTE: ONE CONVENTIONAL TRAINING GROUP PARTICIPANT W AS NOT INCLUDED INTHE SIMULATOR TEST . ERROR BARS REPRESENT STANDARD ERROR. 
The range test scores showed a similar pattern whereby the conventional, simulator, and CDL-focused training groups all displayed a drop in mean scores on the BTW range test from the conclusion of entry level testing to follow-up testing. Though the informal training groups BTW range test scores increased over this same period, the conventional and simulator training groups both displayed a similar drop in simulator range test scores. These results should be viewed with respect to the limitations of the s mall sample size of all groups.

\section{DISCUSSION}

Determining the efficacy of training approaches requires the assessment of information retention and performance benefits well after the training has been completed. The current study attempted to do that and, though data were lacking to conduct the statistical analyses needed to confidently assess efficacy, the study provides descriptive statistics and a model for conducting future studies.

This data presented herein highlighted an evaluation of post-licensure performance as a function of training approach. Further analyses investigating longitudinal effects can be found in [3] including participants' self-evaluation of their training method, driving performance after working as a Class A CDL driver, safety performance, and supervisory ratings. The current study focused on a follow-on evaluation with on the road and range tests for participants.

A general finding from the current analysis was that most of the follow-up BTW and road and range test scores were lower than the original scores for the entry-level tests. However, both conventional and simulator group participants performed better on the follow-up road tests than did participants from the informal and CDL-focused groups suggesting the lasting effects of training from more intensive truck driver training programs (both conventional and simulator). Future research is recommended to expand upon this research, by including a larger sample of drivers, to further evaluate the long term effects that various training approaches have on information retention and objective driving skill performance.

\section{REFERENCES}

[1] Hartman, K., Pritchard, R., Jennings, K., Johnston, J., Knipling, R.R., et al., Commercial Vehicle Safety - Technology and Practice in Europe (Document no. FHWA-PL-00-010), USDOT, FHWA, Office of InternationalPrograms: Washington, DC, 2000.

[2] Robin, J.L., Knipling, R.R., Tidwell, S.A., McFann, J., Derrickson, M.L., \& Antonik, C., FMCSA Commercial Truck Simulation Validation Study Phase I pilot test: Driving scenario definition and development. Driving Simulation Conference, North America 2005. Orlando, FL, 2005.

[3] Morgan, J.F., Tidwell, S.A., Medina, A., Blanco, M., Hickman, J.S., \& Hanowski, RJ., Commercial Motor Vehicle Driving Simulat or Validation Study (SimVal): Phase II (Report No. FMCSA-RRR-11-014). Federal Mot or Carrier Safety Administration: Washington, DC, 2011. http://www.fmcsa.dot.gov/facts-research/researchtechnology/report/Simulator-Validation-Study-report.pdf 